\title{
Holistic Module Learning: An Experiment in Teaching Reform of Basic Education in China
}

\author{
Fengping Zhao
}

Shandong 271 Education Group, Shandong, China

\begin{abstract}
In the context of China's social transformation and educational reform, addressing the problems of fragmented and ineffective learning in traditional teaching modes and enhancing students' academic levels and developing their comprehensive abilities through structured classroom learning have become critical issues in educational reform. The holistic module learning model emerges in this context as the times dictate. It promotes the development of a systematic and holistic view of knowledge for all subjects by teachers and students. Students use major concepts to connect disparate knowledge, skills, and methods in order to develop a persistent and transferable understanding of knowledge and cognitive and noncognitive abilities. The purpose of this paper is to conduct a conceptual analysis of holistic module learning and to discuss its characteristics. The implementation strategies for this model are discussed, as well as the model's significance.
\end{abstract}

Science Insights Education Frontiers 2022; 11(1):1475-1483.

Doi: 10.15354/sief.22.or003

How to Cite: Zhao, F. (2022). Holistic module learning: An experiment in teaching reform of basic education in China. Science Insights Education Frontiers, 11(1):1475-1483.

Keywords: Major Concepts: Module Learning, Holistic Learning, Self-Directed Learning 


\section{Introduction}

7 HE holistic module learning model was developed during China's basic education reform. In the 1980s, the Chinese education community began to focus on the study of holistic module learning, and the model had a significant impact on teaching reform. Recently, as a result of the new curriculum reform, holistic module learning has emerged as a new trend in elementary education. It aims to overcome the shortcomings of traditional fragmented modes of instruction, to structure classroom instruction around major concepts in modules, and to develop students' higher-order skills such as inquiry and self-directed learning. Numerous successful implementation cases have emerged, the most illustrative of which is Shandong 271 Education Group's fruitful practice. Through its years of application, the holistic module learning model has aided in the reform of students' learning contents and methods as well as the enhancement of students' learning efficacy. The purpose of this paper is to define and elaborate on the three fundamental elements of holistic module learning, namely taskdriven learning, situational experience, autonomous inquiry, and promotive transfer. The implementation strategies for the classroom procedure, group study, and assessment system are discussed, as is the model's significance in China's educational and teaching reform.

\section{Conceptual Analysis of Holistic Module Learning}

Teachers and students must employ major concepts to develop a holistic picture of information in each subject and combine different knowledge, skills, and methodologies in order for students to have a comprehensive and transferable understanding of knowledge. Major concepts, module learning, and holistic learning are the three basic elements.

\section{Major Concepts}

According to Ausubel's (1960) notion of "advance organizers," the rapid collection and development of knowledge in the new era demands people carefully pick significant concepts and prioritize them as critical information in their respective fields. They contribute to the development of frameworks for learning and knowledge transmission, hence increasing the efficacy of learning. Major ideas in the holistic module learning model refer to abstracted thoughts or laws derived from tangible information. They

(c) 2022 Insights Publisher. All rights reserved.

Creative Commons NonCommercial CC BY-NC: This article is distributed under the terms of the Crea(c)
$\mathrm{nc} / 4.0 /$ ) which permits non-commercial use, reproduction and distribution of the work without further permission provided the original work is attributed by the Insights Publisher. 
make extensive generalizations about the nature and features of things, as well as the links between concepts. For example, the statement "the composition and structure of matter determine its qualities" is a significant notion concerning the links between the composition, structure, and properties of matter that are characteristic of being broad, abstract, universal, and far-reaching.

To stimulate students' inquiry and discussion, learning with a focus on major concepts needs the development of basic questions that align with the module's objectives. The fundamental questions are not intended to be answered by pupils using previously acquired knowledge. On the contrary, they are composed of open structures capable of eliciting prolonged thought about major concepts. With traditional learning methods, questions are so fragmented and limited in scope that students can rapidly locate ready-made or limited responses. This impairs kids' ability to think critically.

\section{Module Learning}

Module learning is a teaching strategy that splits learning materials into broad modules rather than discrete and fragmented courses and integrates learning content and activities into a holistic process. This teaching concept was introduced into China following the May Fourth Movement (an anti-imperialist and anti-feudal movement initiated by patriotic youth in 1919, signifying China's cultural transition into the Modern Era). Since then, the practice of preparing textbooks per unit (a teaching idea akin to a "module" in China) has continued until the present day. Module learning started to get more attention in the 1980s at all levels of school.

In module learning, a module is a set of related parts organized around a shared major subject or topic that functions as a reasonably self-contained unit inside the textbook. In learning practice, a module is a collection of well-organized learning exercises that serve a specific purpose. Additionally, the relationships between modules are emphasized to assist pupils in digesting learning materials logically and methodically.

\section{Holistic Learning}

Being holistic in this learning paradigm entails developing the module's knowledge framework from a macro perspective and integrating the module's interrelated knowledge elements. Holistic learning is a method founded on the ideas of mutual relevance between learning content and knowledge integrity and learner engagement. It promotes independent learning and the harmonious development of intelligence, emotion, and spirit through tactics such as situational learning, effective integration of instruction and practice, and the construction of thinking frameworks (Wang, 2019).

\section{Holistic Module Learning}

Based on the foregoing research, we conclude that holistic module learning is a studentcentered learning paradigm that uses major concepts to re-integrate learning content while emphasizing learning autonomy and integrity. Task-driven learning, situational 
experience, autonomous enquiry, and promotive transfer are the four distinguishing features of this learning approach. It aids students' understanding of core ideas, logical structure, and practical value of subject information, as well as cultivates students' thinking capacity through a comprehensive cognitive process that includes self-directed study, conversation, critique, application, and generation.

\section{Characteristics of Holistic Module Learning}

\section{Task-Driven Learning}

Task-driven learning is a constructivist-inspired method that breaks down learning materials into specific and quantifiable learning tasks in order to help students build problem-solving abilities through exploratory and cooperative learning (Xia \& $\mathrm{Hu}, 2016$ ). The task is a critical component of the holistic learning model because it connects the various stages of the teaching process and successfully addresses the issue of unfocused and fragmented classroom learning. When students acquire module content through specific tasks in situational contexts, their interest in learning is piqued and their selfmotivation to study is boosted.

In this learning module, a task is an activity designed to help students achieve a learning objective. For example, when teaching "similar triangles" in junior secondary mathematics, the assignment is "measuring the height of the teaching building," which requires students to apply their knowledge of similar triangles to conceptualize, implement, and test the measurement method. There are numerous task types. They can be highly intellectual activities, such as giving a speech or mimicking a job fair, hosting a discussion, creating a picture, singing a song, having a concert, or playing a ball game.

The critical component of task design is self-driven, that is, establishing the internal motivation for a student to learn rather than being forced to study. Students' requests for additional knowledge and increased skills increase as they complete the work. The following principles should guide the task design process:

\section{Educational}

Open and relevant learning challenges should be created to increase students' competencies in core areas based on their prior knowledge.

\section{Interesting}

To create adaptable and appealing learning assignments, task designers should choose and use fascinating and understandable real-world scenarios.

\section{Challenging}


Tasks should be of a sufficient level of difficulty to require significant thought and careful execution. They should not be too simple for students to find ready solutions, nor should they be excessively difficult for students to finish.

\section{Relevance}

Students can build their own knowledge structure and improve their learning skills by completing assignments that focus on important topics and are clearly linked to the learning elements in the curriculum.

\section{Integrity}

In each lesson, there should only be one full task. Teachers should transfer task plans over to students after establishing the technique and instructions for tasks so that they can complete them independently and experience the activities' integrity. Teachers should respect students' intellectual abilities and avoid pursuing one-size-fits-all outcomes.

\section{Situational Experience}

Situational learning is a teaching approach that uses real-world situations to create instructional settings. Contextualizing learning encourages students' interest and initiative in the classroom. Teachers can create scenarios using physical items, visuals, activities, language, the linkages and conflicts between established and new concepts, and prior knowledge. The development of learning settings should incorporate a variety of aspects, including personal experience, subject-matter qualities, difficulties, and even emotion (Jia, 2000). Authenticity is the most crucial prerequisite for situation construction. Genuine experience has the potential to make learning both intriguing and effective.

\section{Autonomous Inquiry}

Genuine and comprehensive learning entails not only the completion of instructional materials but also self-directed inquiry, which may include questioning, criticism, collaboration, and discovery (Kang, 2017). Autonomous inquiry broadens students' conceptual horizons and piques their interest in the essence of things. Through comprehensive module learning, students develop their own understanding of the world through utilizing previous information. They establish the meaning of existence, discover the order of the world, and develop reasoning autonomously during this process. Teachers guide students' learning rather than limit their knowledge, practice, and imagination.

\section{Promotive Transfer}


The core feature of holistic module learning is its emphasis on knowledge transferability. It guides learners via a sequential procedure that results in information transfer. Students first acquire key knowledge for each module, guided by learning objectives; next, they expand their understanding of major concepts in practice through task implementation; and finally, it is transferred to and implemented in new learning scenarios. This learning strategy enables students to build higher-order thinking skills through the constant absorption of knowledge and the development of new knowledge through practice.

\section{Implementation Strategies of Holistic Module Learn- ing}

Holistic module learning methodologies encompass not only classroom activities, but also students' self-organized group studies. Additionally, the multi-level evaluation method effectively facilitates the application of holistic module learning.

\section{Creating a Standardized Procedure for Holistic Module Learning in the Classroom}

In general, the classroom method for learning about a whole module is broken down into four stages: overall perception, inquiry and construction, application and transfer, and reconstruction and expansion.

\section{Overall Perception}

Students' remarkable experiences result in profound education. Teachers should present or create authentic settings for students to experience the context of learning activities and become self-motivated to pursue further investigation. In this first step, learning objectives and tasks are developed around the module's primary ideas.

\section{Inquiry and Construction}

Students define the knowledge, methods, and abilities that should be mastered in the current module through self-directed and cooperative learning. They establish critical links between knowledge points and abilities on their own. Students then investigate the logic of knowledge and develop the inquiry challenge.

\section{Application and Transfer}

Knowledge and abilities should be applied in relation to real-world demands, and learning challenges should be tailored to solve practical problems. Students constantly examine earlier teachings and renew their understanding, methods, and skills as they complete assignments in order to develop new ones. Additionally, they communicate ideas 
based on freshly produced knowledge, methodologies, and abilities and apply them to novel social circumstances and issues. Such cycles of understanding and making can keep giving you new ideas about the subject's major concepts.

\section{Reconstruction and Expansion}

Students recall the module's primary concepts, evaluate the module's achievement of learning objectives, and describe problem-solving techniques by focusing on the module's major topics. Students reconstruct their knowledge structures, create mental maps, and optimize their learning methods across all topics by assessing completed activities, solved issues, and new gains.

\section{Encouraging Students' Self-Directed and Cooperative Learning}

Because one of the key goals of holistic module learning is to foster students' autonomy and self-regulation in the classroom, study groups are given a high priority. The study group's organization should be based on the principle of homogeneity between groups and heterogeneity within the group, which implies that each group should include people with a range of academic backgrounds, perspectives, learning styles, hobbies, genders, and personalities. Both individuals and groups have the option of determining the group's composition. The study group is the most fundamental organizational structure for implementing holistic module learning, with group study being the most prevalent type of cooperative learning. Additionally, each subject should have a specialty study group comprised of one student from each study group. As a result, each student in the class has the opportunity to join a specialty study group. They help teachers and act as academic leaders for group members in their assigned courses.

Prior to class, the specialty study group leader shall facilitate discussions about the module's learning contents and learning tasks, formulate the module's learning plan, objectives, and strategies with the assistance of the learning program, and then distribute the agreed-upon plan to each study group. Cooperative learning occurs in the classroom through study groups. Self-study, cooperative learning, and inquiry are alternated. Everyone thinks and talks freely, and eventually, the group reaches consensus on a certain question or topic. Following class, the study group uses evening self-study time or any other available time to assess each group member's learning outcome in order to ensure that team support is always available and that no student falls behind.

\section{Establishing a Multi-Dimensional Assessment System}

The school assessment system is crucial in influencing student learning. To facilitate students' holistic growth, the holistic module learning model assesses students' performance across multiple dimensions, including academic accomplishment, physical and mental health, personality development, and social skills. This is in contrast to tradi- 
tional evaluation, which uses examination results as the sole criterion. Additionally, holistic module learning emphasizes formative evaluation over summative assessment. In a single term, a student's overall assessment consists of a weekly assessment, a monthly performance report, and a terminal assessment. Exam results alone cannot adequately reflect students' attitudes, commitments, learning styles, innovative dispositions, and practical abilities. Educational assessment is a valuable tool for assisting students in their learning. The use of a student-centered and multidimensional scientific evaluation system can make a big difference in competence-based education and the overall development of children (Gardner, 2008).

\section{The Significance of Holistic Module Learning}

\section{Advancing Classroom Teaching Reform}

The holistic module learning model shifts the emphasis of the teacher's class design away from imparting knowledge and toward developing student subject competence; away from accumulating knowledge and toward searching for the logic behind knowledge; and away from overemphasizing learning results and toward considering both the learning process and results. All of these modifications enable students to engage in deep learning. In typical classroom instruction, learning content is frequently fragmented into unconnected information points that lack organization, resulting in shallow learning and low efficiency (Chen \& Tang, 2018). Deep learning, on the other hand, asks students to think about how different topics are linked and gives them a lot of tools for building their own knowledge structures and complex problem-solving skills.

\section{Developing Brand New Teacher-Student Relationships}

The classroom is student-centered rather than teacher-centered in holistic module learning. The teacher functions more as a designer of the learning process, integrating diverse curriculum resources and creating appropriate learning environments and engaging learning tasks for students, while students are the primary actors in the classroom, with ample time and space for self-directed learning, cooperation, and inquiry. This does not mean that teachers' workloads are reduced; rather, the teaching requirement that a greater emphasis be placed on the learning process than on the learning outcomes adds to the complexity of teachers' work. Additionally, the holistic module learning approach emphasizes and strengthens the relationship between teachers and students, necessitating increased professional capabilities. Thus, teacher-student connection and exchange contribute to their mutual development.

\section{Prompting the Transformation of the Talent Develop- ment Mode}


The purpose of conventional education is straightforward: to prepare students for school progression. However, teachers are supposed to place a greater emphasis on pupils' comprehensive and balanced development in terms of intelligence, skills, and personalities under the holistic module learning paradigm. They assist students in developing and implementing their learning objectives and in fostering their self-concept by guiding them through the metamorphosis from poor self-esteem to self-confidence and finally to self-reliance. Additionally, student growth is diverse and tailored depending on each kid's unique abilities and interests. In this learning style, the learner is viewed as an aim rather than a means. The incorporation of educational technology enhances the efficacy of holistic module learning in the development of individualized talent.

In sum, holistic module learning has the potential to not only change traditional learning methodologies but also pave the way for students' healthy and holistic development. It satisfies the core requirements of China's basic education curriculum reform and proves to be an effective experiment in teaching reform.

\section{References}

Ausubel, D.P. (1960). The use of advance organizers in the learning and retention of meaningful verbal material. Journal of Educational Psychology, 51(5):267-272. DOI: https://doi.org/10.1037/h0046669

Chen, J.J., \& Tang, Y. (2018). Dilemmas and reform in classrooms: from superficial learning to deep learning: Basing on a long-term study of real learning process of students. Research in Educational Development, 38(15):90-96. DOI: https://doi.org/10.14121/j.cnki.10083855.2018.z2.014

Gardner, H. (2008). Frames of Mind: The Theory of Multiple Intelligence (Chinese Edition). Beijing: China Renmin University Press.

Jia, L. (2000). Creating teaching settings and experiencing the beauty of life -- On meth- ods and effects of creating settings in the multimedia course of Chinese. Chinese Teaching in Middle Schools, 2000(11):23.

Kang, X. (2017). Attaching importance to the process of learning and making learning happen - Reflection on and practice of constructing effective mathematics classrooms in primary schools. Correspondence of the Teaching of Mathematics, 2017(19):52-53.

Wang, H.Q. (2019). On holistic teaching. global education, 2019(4):34-44.

Xia, N. \& Hu, B. (2016). Research on task driven tacit knowledge learning. Science Research Management, 2016(5):141-149. DOI: https://doi.org/10.19571/j.cnki.1000$\underline{2995.2016 .05 .017}$ 